\title{
Mobility, Chemistry, and Prevalence of Shale-Derived Organic Carbon in an Alluvial Floodplain
}

\author{
PATRICIA M. FoX ${ }^{1 *}$, MARKUS BILL ${ }^{1}$, KATHERINE
} HECKMAN $^{2}$, MARK CONRAD ${ }^{1}$, CHRISTIAN DEWEY ${ }^{3}$, CAROLYN ANDERSON ${ }^{4}$, MARCO KEILUWEIT ${ }^{4}$, SCOTT FENDORF $^{3}$, AND PETER S. NICO ${ }^{1}$

${ }^{1}$ Earth and Environmental Sciences Area, Lawrence Berkeley National Laboratory, Berkeley, CA 94720;

*pmfox@lbl.gov

${ }^{2}$ USDA-Forest Service, Northern Research Station, Madison, WI

${ }^{3}$ Department of Earth System Science, Stanford University, Palo Alto, CA

${ }^{4}$ School of Earth \& Sustainability and Stockbridge School of Agriculture, University of Massachusetts Amherst, Amherst, MA

In mountainous watersheds, rivers transport both mineral and organic matter from steeper terrain and deposit it into floodplains where river water moves more slowly, meandering across broad unconfined valleys. The floodplains of meandering rivers are biologically and hydrologically dynamic zones may serve as both a large sink for carbon, and a source of dissolved carbon input to the river. There are three primary sources of organic carbon (OC) in floodplain sediments: (1) river-deposited vegetative debris, (2) litter input from riparian-zone vegetation, and (3) mineral-associated OC deposited by the river from erosion of upland soils and rocks. In a shale-dominated landscape, shale kerogen may be an important source of mineral-associated OC. Shale-derived kerogen and litter-derived OC each have distinct initial chemical characteristics and potentially different reactivity, which may affect their ultimate fate in the river system with respect to storage, mineralization, and degradation. This study focuses on the East River, a highelevation mountainous watershed near Gothic, Colorado, USA, where Cretaceous Mancos shale is the dominant bedrock. Through the use of sediment density separations, extractions, radiocarbon measurements, and synchrotron carbon spectroscopy, we provide information on the abundance, chemistry, and mobility of shale-derived OC in floodplain sediments of an active and cut-off meander. Further, we examine the role of seasonally and spatially dynamic redox status on OC mobility in the floodplain and export to the river. This study demonstrates the important contribution of shale-OC, particularly in environments with low litter inputs, and underscores the role of sediment redox status as a control on OC mobility. 